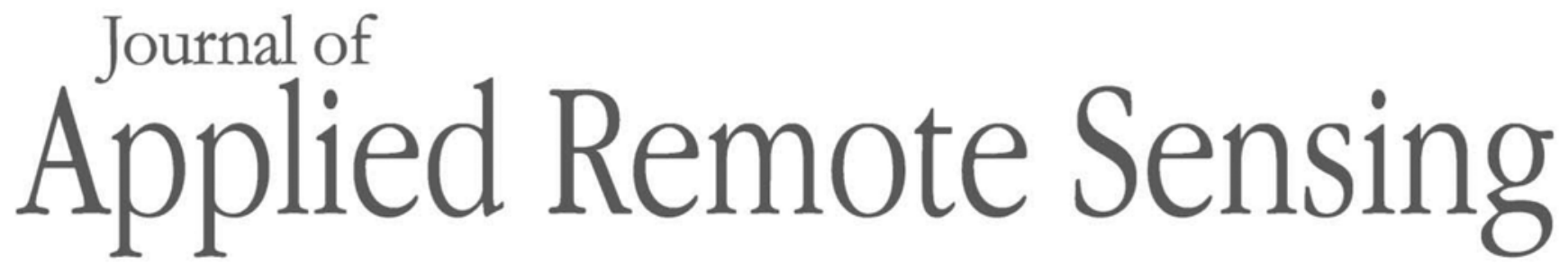

RemoteSensing.SPIEDigitalLibrary.org

\title{
Strata-based forest fuel classification for wild fire hazard assessment using terrestrial LiDAR
}

\author{
Yang Chen \\ Xuan Zhu \\ Marta Yebra \\ Sarah Harris \\ Nigel Tapper
}




\title{
Strata-based forest fuel classification for wild fire hazard assessment using terrestrial LiDAR
}

\author{
Yang Chen, ${ }^{\mathrm{a}, \mathrm{b}, *}$ Xuan Zhu, ${ }^{\mathrm{a}}$ Marta Yebra, ${ }^{\mathrm{b}, \mathrm{c}}$ Sarah Harris, ${ }^{\mathrm{a}}$ and \\ Nigel Tapper ${ }^{a}$ \\ ${ }^{a}$ Monash University, School of Earth, Atmosphere and Environment, Faulty of Science, \\ 9 Rainforest Walk, Wellington Road, Clayton, Victoria 3800, Australia \\ ${ }^{\mathrm{b}}$ Bushfire and Natural Hazards CRC, 340 Albert Street, East Melbourne, Victoria 3002, Australia \\ ${ }^{\mathrm{c}}$ Australian National University, Fenner School of Environment and Society, \\ College of Medicine, Biology and Environment, Canberra, ACT 2601 Australia
}

\begin{abstract}
Fuel structural characteristics affect fire behavior including fire intensity, spread rate, flame structure, and duration, therefore, quantifying forest fuel structure has significance in understanding fire behavior as well as providing information for fire management activities (e.g., planned burns, suppression, fuel hazard assessment, and fuel treatment). This paper presents a method of forest fuel strata classification with an integration between terrestrial light detection and ranging (LiDAR) data and geographic information system for automatically assessing forest fuel structural characteristics (e.g., fuel horizontal continuity and vertical arrangement). The accuracy of fuel description derived from terrestrial LiDAR scanning (TLS) data was assessed by field measured surface fuel depth and fuel percentage covers at distinct vertical layers. The comparison of TLS-derived depth and percentage cover at surface fuel layer with the field measurements produced root mean square error values of $1.1 \mathrm{~cm}$ and $5.4 \%$, respectively. TLS-derived percentage cover explained $92 \%$ of the variation in percentage cover at all fuel layers of the entire dataset. The outcome indicated TLS-derived fuel characteristics are strongly consistent with field measured values. TLS can be used to efficiently and consistently classify forest vertical layers to provide more precise information for forest fuel hazard assessment and surface fuel load estimation in order to assist forest fuels management and fire-related operational activities. It can also be beneficial for mapping forest habitat, wildlife conservation, and ecosystem management. (C) 2016 Society of Photo-Optical Instrumentation Engineers (SPIE) [DOI: 10.1117/1.JRS.10.046025]
\end{abstract}

Keywords: terrestrial LiDAR scanning; geographic information system; canopy height; Eucalyptus spp.

Paper 16461 received Jun. 22, 2016; accepted for publication Nov. 11, 2016; published online Dec. 7, 2016.

\section{Introduction}

The development of accurate and reliable methods to quantify forest fuels is an ongoing requirement of government and fire authorities, due to the continual need for improvement in fire resource management. ${ }^{1}$ In Australia, fuel characteristics are usually assessed and described in numerical terms by fuel loading, fuel depth, and fuel particle density., ${ }^{2,3}$ Traditional fuel assessment relies on destructive measurement by directly measuring dry weight of total live and dead biomass per unit area, particularly fine litter fuel, ${ }^{4-7}$ often defined in Australia as those fuel particles less than $6 \mathrm{~mm}$ in diameter. This is a required input to the McArthur empirical rate of spread model for eucalypt forests. ${ }^{8,9}$ However, these direct measurements are time and labor intensive. ${ }^{10-14}$ An Australian bushfire study, Project Vesta, identified the importance of fuel structural characteristics in determining fire behavior and ease of suppression, rather than fine fuel load. ${ }^{1}$ Fuel structure is comprised of five layers based on their horizontal arrangement

*Address all correspondence to: Yang Chen, E-mail: yang.chen2@monash.edu

$1931-3195 / 2016 / \$ 25.00$ (C) 2016 SPIE 
and vertical position in the forest profile, including canopy fuels, shrubby elevated fuels, nearsurface fuels, litter fuels (surface fuels), and bark fuels. ${ }^{1}$ Currently, guidelines for fuel structure measurement through visual assessment have been developed for southeastern Australia and Western Australia, through the Overall Victorian Fuel Hazard Assessment Guide and Project Vesta, respectively. The visual assessment of fuel structural characteristics (e.g., fuel depth, height, percentage cover, horizontal continuity, and vertical arrangement) at distinct fuel layers is rapid; however, it can be subjective, inconsistent, and also be restricted by local complex terrain. Therefore, an efficient and accurate method to assess fuel structural characteristics is a significant need in bushfire-related studies and forest fuel resources management. ${ }^{15-18}$

Light detection and ranging (LiDAR) can be used to reconstruct the vertical overstory and understory vegetation arrangement due to its capability of three-dimensional (3-D) measurements with high accuracy. ${ }^{16,17,19,20}$ Airborne laser scanner (ALS)-derived canopy height models have been used to describe canopy height distribution ${ }^{17,21-23}$ and to identify individual tree heights. ${ }^{20,23-26}$ Moreover, LiDAR-derived vertical distribution of forest structures provides a new perspective to describe canopy profile. Recent studies, including, for example, that of Hermosilla et al. ${ }^{27}$ and Jakubowksi, ${ }^{28}$ described vertical profile of forest vegetation using theoretical distribution functions of ALS-derived indices. In these studies, lower vegetation $(<3 \mathrm{~m})$ was excluded in the vertical description of forest structure, and the authors argued the complete vegetation profile including the removal points would not follow the theoretical distribution. However, the lower vegetation including elevated shrubs, near-surface grass, and surface litter fuel are significant fuel structural components, which directly impact fire ignition and its rate of spread. ALS has limitations in detecting understory fuels in multilayered forests, since the emitted laser beams have difficulty in penetrating the upper canopy to hit the ground with the majority of the energy reflected back to the sensor from overstory vegetation. ${ }^{19,29-31}$ In this context, terrestrial LiDAR scanning (TLS) can be used as a substitution of ALS for description of shadowing effected understory vegetation. ${ }^{32}$

Several studies have evaluated the significant improvement of using TLS (e.g., static and mobile TLS) in reducing the shadowing effects of overstory vegetation to detect understory fuel. TLS changes the scanning angles and positions from top of canopy to understory, which allows the majority of energy from laser beams to directly reflect back to the laser sensor from the lower (live and dead) vegetation, and also improves the spatial accuracy up to millimeters. ${ }^{33}$ The survey sizes, however, can be restricted within the given scanning scales (vertical and horizontal) of the survey instruments. ${ }^{32,34}$ Overlapped scans using the static (e.g., tripod mounted) devices are also often found in forest applications in order to increase the size of the scanning sites and also to improve the accuracy of further vegetation away from the scanning positions. ${ }^{35}$ The overlapping scans are not necessary when using mobile TLS, since it utilizes a navigation module to determine the position of each laser beam when the laser takes measurements of the environment. ${ }^{36}$ The vegetation measurements derived from TLS can be utilized as a basis for assessing biophysical tree parameters that include tree heights, diameter at breast height (DBH), woody volume, and leaf area. ${ }^{37,38}$

Studies found that static TLS-derived mathematical morphology techniques (e.g., Houghtransformation, circle approximation, and locating arc center algorithm) could be used to estimate DBH accurately and consistently. ${ }^{14,39-45}$ A proof of concept test conducted by Ryding et al. ${ }^{36}$ demonstrated the ability of mobile TLS (including Zebedee and FARO) to extract DBH and stem position using circle approximation. The DBH and the stem position derived from Zebedee achieved a root mean square error (RMSE) value of 1.5 and $2.1 \mathrm{~cm}$, respectively. The maximum measurement error stated by the manufacturer is $3 \mathrm{~cm}$ at a range up to $10 \mathrm{~m} .{ }^{46}$ Consequently, mobile TLS, representation of tree trunks can assist forest fuel strata classification.

Other studies have described estimating woody volume and leaf area by reconstructing tree structures using TLS-based 3-D modeling. For instance, tree topology skeleton algorithms for estimating woody volume of main branches were proposed by Gorte and Pfeifer. ${ }^{47}$ They fitted a sequence of overlapping cylinders in point clouds to model stem and some major branches of a tree. Côté et al ${ }^{41}$ applied the 3-D Monte Carlo ray-tracing model Rayspread ${ }^{48}$ reconstruction modeling to estimate the woody area and the leaf area. These methods, however, have yet not been validated with ground data. ${ }^{33,42}$ Hosoi and Omasa ${ }^{49}$ used a voxel-based 3-D model to estimate leaf area density (LAD). In their study, the best LAD estimates showed errors of 
$17 \%$ at minimum horizontal layer thickness and $0.7 \%$ at the maximum thickness, respectively. $\mathrm{Xu}$ et al. ${ }^{50}$ represented tree trunks and main branches using polygonal meshes derived from TLS. This approach has only been tested by scanning of elm, ash, and cottonwood trees. ${ }^{50}$

Consequently, current methods developed to detect information of understory vegetation have restrictions on operational use to assess forest fuel structures, because they are invalid for fuel strata-based classification, tree species, or specific forest types. For bushfire-related studies, using TLS to classify fuel structures and quantify understory forest fuel structural characteristics (e.g., depth, cover, and volume) is still in an early stage. Litter-bed depth highly varies among plots; TLS is more sensitive to capture the height variation than traditional point intercept sampling. ${ }^{38}$ Loudermilk et al. ${ }^{38}$ also found TLS voxel-based fuel volume estimates were linear correlated with biomass and leaf area distribution for individual shrubs when influenced by species, size, and plant section. A transition from grass clumps, low forbs, and shrubs to grass seed heads and taller shrubs was determined by a derivative function on the frequency values of the fuel height $(<0.5 \mathrm{~m})$ distribution derived from TLS. ${ }^{51}$ Marselis et al. ${ }^{52}$ used the circle fitting method to identify the tree trunks from elevated shrubs in a young open eucalypt forest. Their study successfully separated distinct vertical fuel layers, including canopy, tree trunks, elevated shrubs, and near-surface vegetation, according to vertical connection of laser point's representation in forest vegetation. This method, however, was only assessed in a simple-structured young forest that has flat terrain and relatively low overstory and understory vegetation. More tests are essential in dense and mature forests with complex terrain features.

Our study proposed an integrated method of TLS and GIS for an automatic classification of eucalypt forest fuel structures and quantification of understory fuel structural characteristics, including surface fuel depth and percentage cover of fuel at individual fuel layers. This method provided an efficient and consistent alternative to visual assessment for fuel layer classification in multilayered eucalypt forest with complex terrain features, in order to assist fuel hazard assessment, forest fuels management, and bushfire-related activities across the study area.

\section{Materials and Methods}

\subsection{Study Area and Data}

The study area is located at Upper Yarra Reservoir, Victoria, in southeastern Australia $\left(37^{\circ}\right.$ 34'32'S, 145 $56^{\prime}$ '17' E) (Fig. 1), which is a eucalyptus open forest with a shrubby understory. It has a large range of indigenous eucalypt species which include, manna gum (e.g., Eucalyptus viminalis), gray gum (e.g,. Eucalyptus cypellocarpa), messmate (e.g., Eucalyptus obliqua), peppermint (e.g., Eucalyptus croajingolensis, Eucalyptus dives, Eucalyptus elata, and Eucalyptus radiata), silvertop (e.g., Eucalyptus sieberi), stringybark (e.g., Eucalyptus baxteri, Eucalyptus cephalocarpa, and Eucalyptus globoidea), and candlbark gum (e.g., Eucalyptus rubida), and mixed understory species (e.g., Calochlaena dubia, Acacia dealbata, Acacia myrtifolia, and Coprosma quadrifida). The elevation ranges from 219 to $1205 \mathrm{~m}$; the slope ranges from 0 deg to $60 \mathrm{deg}$; the average annual rainfall is $\sim 1122 \mathrm{~mm}$ and the main soil type is clay loam.

Our study sites consisted of six plots of $50 \mathrm{~m} \times 50 \mathrm{~m}$ with different terrain features and fire histories. Controlled burns have been conducted as a typical fuel-management activity in this area, and wildfires also occurred over time after recovery from the Black Friday fires of January 13th, 1939. Plots 1 2, and 3 experienced wildfires in February 2009; plots 4, 5, and 6 underwent controlled burns in March 2010, April 2008, and April 2007, respectively.

The TLS data covering these six plots were acquired from April to May 2015 using a Zebedee 3-D mapping system developed by CSIRO Australia. The device consists of a lightweight laser scanner with a maximum $30 \mathrm{~m}$ scanning range, and a microelectromechanical systems inertial measurement unit mounted on a simple spring mechanism. ${ }^{46}$ As an operator holding the device moves through the environment, the scanner loosely oscillates about the spring, thereby producing a rotational motion that converts the laser's inherent two-dimensional scanning plane into a local 3-D field of view. Walking slowly through each plot allows detailed, 


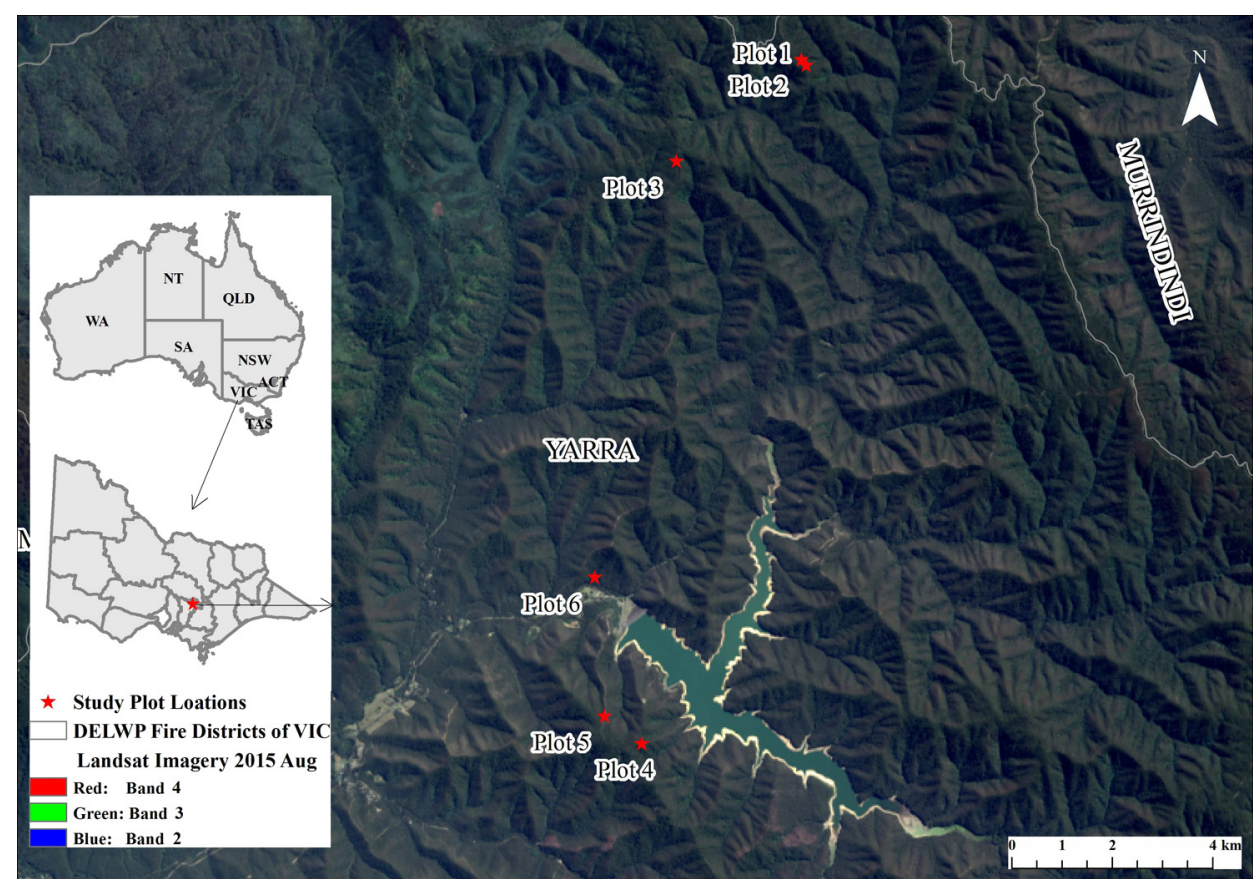

Fig. 1 Study plot locations.

spatially extensive laser data to be collected. The scanning time is about 20 to $30 \mathrm{~min}$ for each plot depending on the accessibility and the local topography and the trajectory; point density can be increased by increasing scanning time.

Field data, including fuel depth (height) and percentage cover at surface fuel layer, nearsurface fuel layer, and elevated fuel layer, were collected simultaneously with the TLS survey. For each plot, random samplings were chosen in order to validate the accuracy of fuel assessment derived from the TLS data. The sample size for each plot varies from 5 to 8 depending on the local environment and accessibility. The sampling fuels were directly measured and assessed within a $1 \mathrm{~m} \times 1 \mathrm{~m}$ frame. The surface fuel depth $(\mathrm{cm})$ was directly measured in areas where near-surface fuels did not obscure the litter using a simple depth gauge-a $15-\mathrm{cm}$ circular disk with a ruler through a slot in the center. ${ }^{53}$ The finalized depth was determined by averaging five measurements within the frame. The depth was determined by an average value of five measurements at each site and fuel coverage was assessed visually. Both fuel characteristics were collected based on the criteria from Victorian Overall Forest Fuel Hazard Assessment Guide.

\subsection{Methods}

The integration between LiDAR and the GIS-based method for an automatic forest fuel strata classification can be described in the following processing steps: converting elevation data to height values ( $Z$ to $H$ conversion), fuel structure classification, and LiDAR-derived fuel characteristics (Fig. 2). These processing procedures were scripted and automated in ArcGIS ModelBuilder. The algorithm is illustrated as below.

\subsubsection{Z to $H$ conversion}

After the LiDAR point clouds are extracted for the selected area, a digital elevation model (DEM) is generated which is used to convert the elevation value of each point $(Z)$ to its height value above the bare earth $(H)$. The DEM is generated through interpolation according to the lowest point within a $1 \mathrm{~m} \times 1 \mathrm{~m}$ grid in order to maintain consistency with the field measurements. The values of $H$ are calculated by subtracting a smoothed DEM from the $Z$ values for further fuel structure classification and assessment. 




Fig. 2 TLS-derived fuel strata classification.

\subsubsection{Fuel structure classification}

Forest fuel layers are separated and grouped based on the spatial continuity of the forest biophysical knowledge. As shown in Fig. 2, the fuel structure classification method involves the following steps:

1. Classification of surface fuel and near surface fuel.

Surface fuel is known as litter fuel, predominantly horizontal in orientation. Nearsurface fuel, on the other hand, has a mixture of vertical and horizontal orientations. The frequency plot of TLS points against height $(h<0.5)^{51}$ tends to follow a bimodal distribution. The division point of the bimodal curve is identified by derivative functions. These two fuel layers are then separated by the identified division point.

2. Initial classification of elevated shrub fuels $(0.5$ to $2 \mathrm{~m}$ ) and overstory fuels (greater than $2 \mathrm{~m}$ ).

The fuel layer classification based on only the height information is illustrated in Fig. 3. By applying the initial classification directly to the LiDAR points, tall shrub fuels may be incorrectly assigned as overstory fuels; low shrub fuels may also be misclassified as near-surface fuels; trunks cannot be classified by this simple step which 


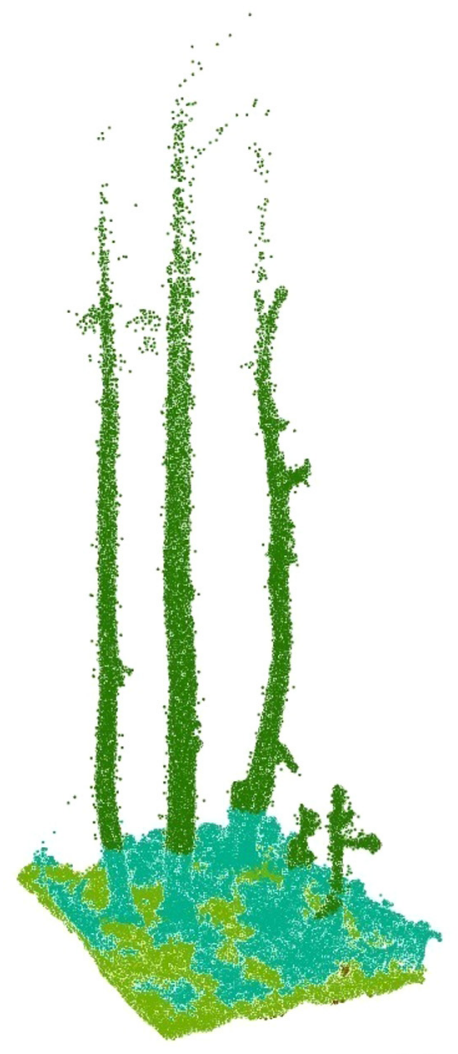

(a)

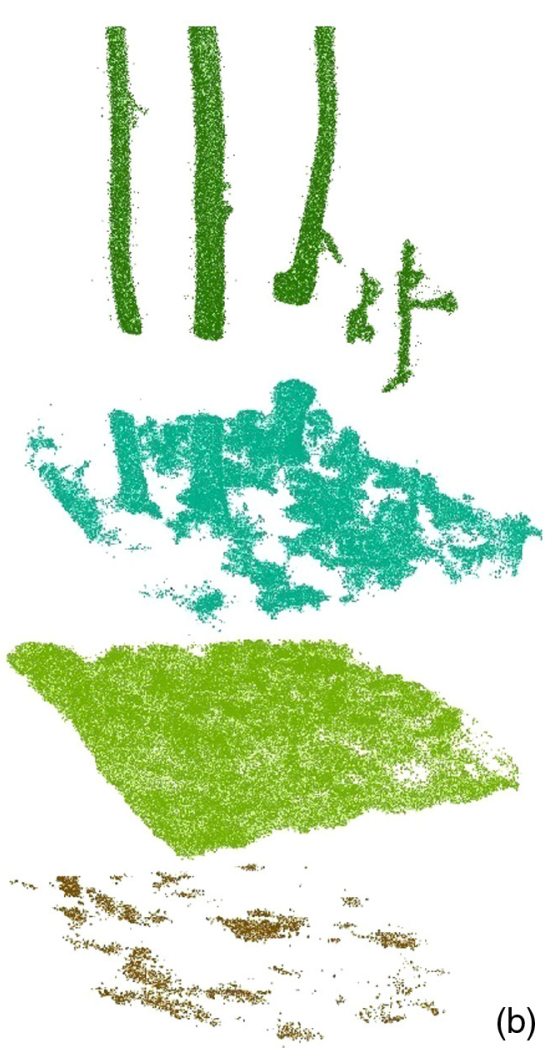

(b)

Fig. 3 Fuel layer classification based on vertical height ranges. (a) An overview of the initial classification based on height ranges and (b) the initially classified fuel strata from top to bottom, including overstory fuel, elevated fuel, near surface fuel, and surface fuel.

creates the difficulty of separating the trunks from overstory fuels. These misclassified and unclassified points need to be reassigned according to their vertical and horizontal continuity.

3. Horizontal slicing the initially classified laser points into groups based on a height interval.

Diameters of tree trunks do not change much within the 1-m interval of height. ${ }^{47}$ The smaller the interval requires longer processing time. For the processing efficiency, $1 \mathrm{~m}$ is chosen as the height interval; each sliced point layer $(l)$ has $1 \mathrm{~m}$ height thickness. The sliced point layers will be used for the reference tree trunk identification where $l_{i}$ ranges from 0 to the maximum height of the canopy and $i$ is the number of height intervals.

4. Identification of reference trunks through locating closest points between two of the discontinued slices as shown in Figs. 4(a)-4(c).

The two slices are selected from the initially classified overstory fuels with the height range between $2 \mathrm{~m}$ (minimum height of the overstory in the study area) and $h$ (the minimum height of the tree branches). The $h$ values can be estimated based on empirical information (e.g., the species and the forest age). We assume that trunks from the two sliced point layers have linear relationships when they are projected to two dimensions according to the $x$ and $y$ coordinates of the laser points. For example, in plot 1 , slice $l_{3}$ with the height range of 2 to $3 \mathrm{~m}$ is shown in Fig. 4(a) and slice $l_{9}$ with the height range from 8 to $9 \mathrm{~m}$ is shown in Fig. 4(b). The reference tree trunks can be identified by searching for the closest points within a threshold, $r$. The threshold $(r)$ is defined according to the footprint size of the laser system. We used a value of $0.02 \mathrm{~m}$ for $r$ in our calculations. The laser points representing tree trunks from the discontinued slices, as shown in Fig. 4(c), are then used as a reference to search for the trunks from each slice. 


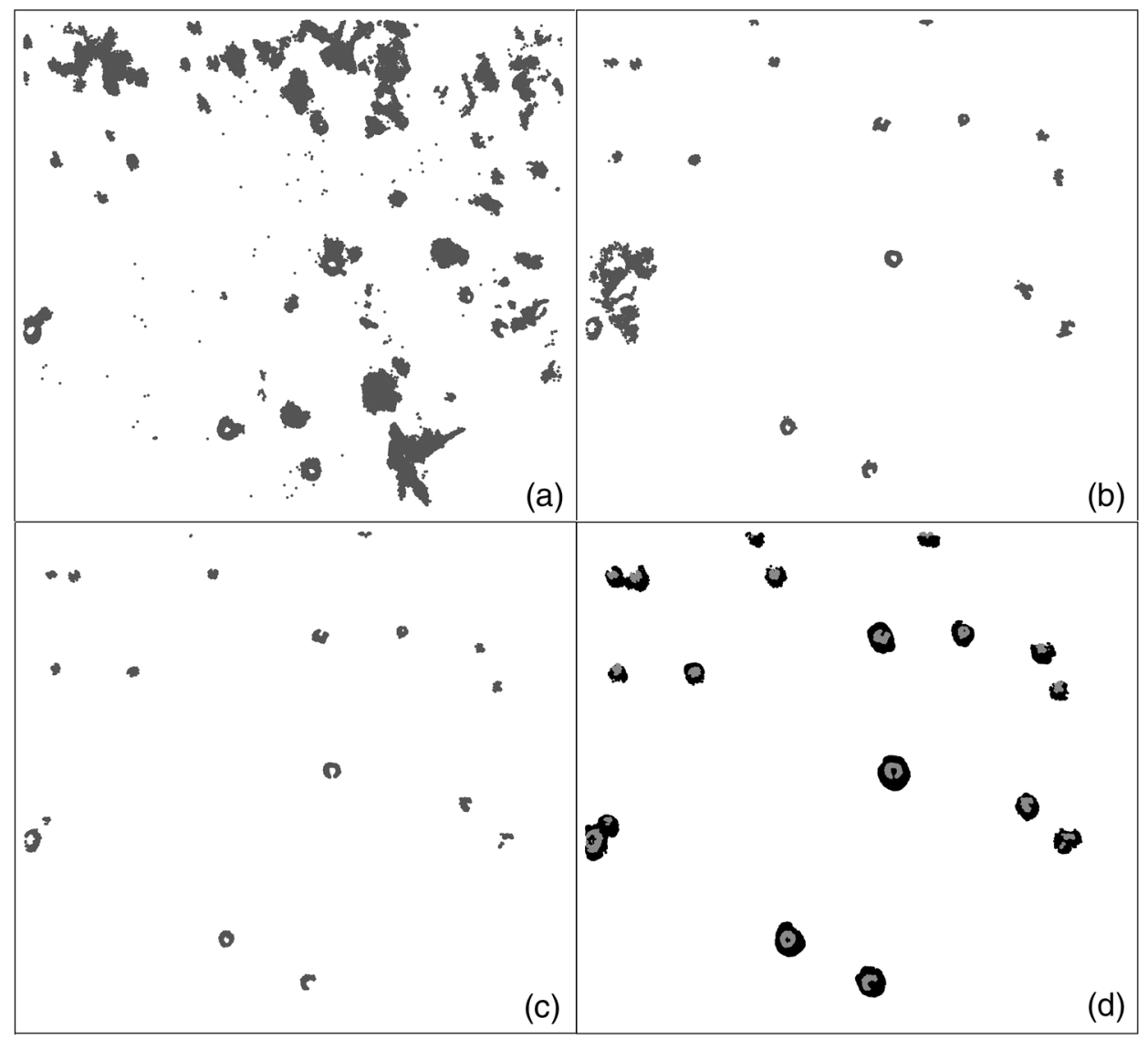

Fig. 4 Reference trunks identification. ( $a$ and $b$ ) The sliced points from layers $I_{3}$ and $I_{9}$, respectively, (c) the reference trunks, and (d) assigned tree trunks (black) according to the reference trunks (gray).

5. Searching tree trunks from other slices using the reference trunks.

Using the above example, the identified points from slice $l_{9}$ act as a reference trunk layer to determine other points from the neighboring slices $l_{10}$ and $l_{8}$ by searching their closest point upward and downward against slice $l_{9}$. The determined points from the neighboring slices then are assigned and grouped into the reference layer to continue the searching procedure upward and downward, until no further trunks can be identified and assigned. The assigned trunks from these slices are then merged together for next classification step [Fig. 4(d)].

6. Elevated shrub reassignment from the incorrectly assigned overstory.

This is accomplished by (a) subtracting laser points of trunks from the slices; (b) searching shrubs at the subtracted slices from the height range between $2 \mathrm{~m}$ to $h^{\prime}$ (the maximum height of the shrubs), progressing upward until no further point can be allocated, thus $h^{\prime}$ can be defined; (c) reassigning the searched shrubs and merging them with the initial elevated fuel class to regroup the elevated fuels together.

7. Identifying tree branches and leaves by subtracting the reassigned elevated shrubs from the rest of the points above $2 \mathrm{~m}$ and assigning them as branches and leaves.

\subsubsection{LiDAR-derived fuel structural characteristics}

After the fuel layer classification, TLS points are used to quantify forest fuel structural characteristics, such as surface fuel depth and percentage cover at distinct fuel layers.

1. A raster image of surface fuel depth is interpolated based on TLS points' height values $(h)$ at surface fuel layer. The cell sizes vary depending on the spatial accuracy and the footprint of the laser scanning system. 
2. Fuel cover is presented as a binary image with the same cell size by classifying the cells into two groups according to the presence (1) or absence (0) of TLS points. The percentage cover of fuel is estimated by calculating the proportion of presence of TLS points in individual fuel layers.

\subsection{Validation}

The accuracy of TLS-derived forest fuel structural characteristics is determined primarily by the accuracy assessment of the TLS-derived surface fuel depth and percentage covers at distinct layers against the field survey data at 45 sampling sites. In some plots, there is only surface fuel or a combination of both surface and near-surface fuel with elevated fuel missing. Therefore, the number of fuel samples was limited, when we took consideration of the availability of three fuel layers (surface, near-surface, and elevated fuel layers) within $1 \mathrm{~m}^{2}$ in the field. TLS-derived fuel properties compared with field sampling data according to the GPS location of each sampling site, since the Zebedee device has a detachable GPS device. In addition, photographs taken at each sampling site were used to verify the location of the plots. The RMSE is applied to validate the accuracy, which is expressed as

$$
\text { RMSE }=\sqrt{\sum_{i=1}^{N} \frac{\left(x_{i}-x_{i}^{\prime}\right)^{2}}{N}},
$$

where $x_{i}$ represents the field data (surface fuel depth and percentage cover at distinct layers) of fuel sample $i, x_{i}^{\prime}$ is defined as the TLS-derived fuel characteristics of fuel sample $i$, and $N$ is the number of fuel samples. The coefficient of determination $\left(R^{2}\right)$ is also calculated as the proportion of the response variable variation that is explained. Moreover, the $P$ value is used to test for statistical significance. In addition, the assumptions and random errors associated with the regression model are also assessed by visualizing the statistical graphics, such as, a histogram of raw residuals and a normal probability plot.

\section{Results}

This study results in three outputs: fuel strata classification, surface fuel depth, and fuel percentage cover at distinct fuel layers. The GIS and TLS-derived method produces a more accurate
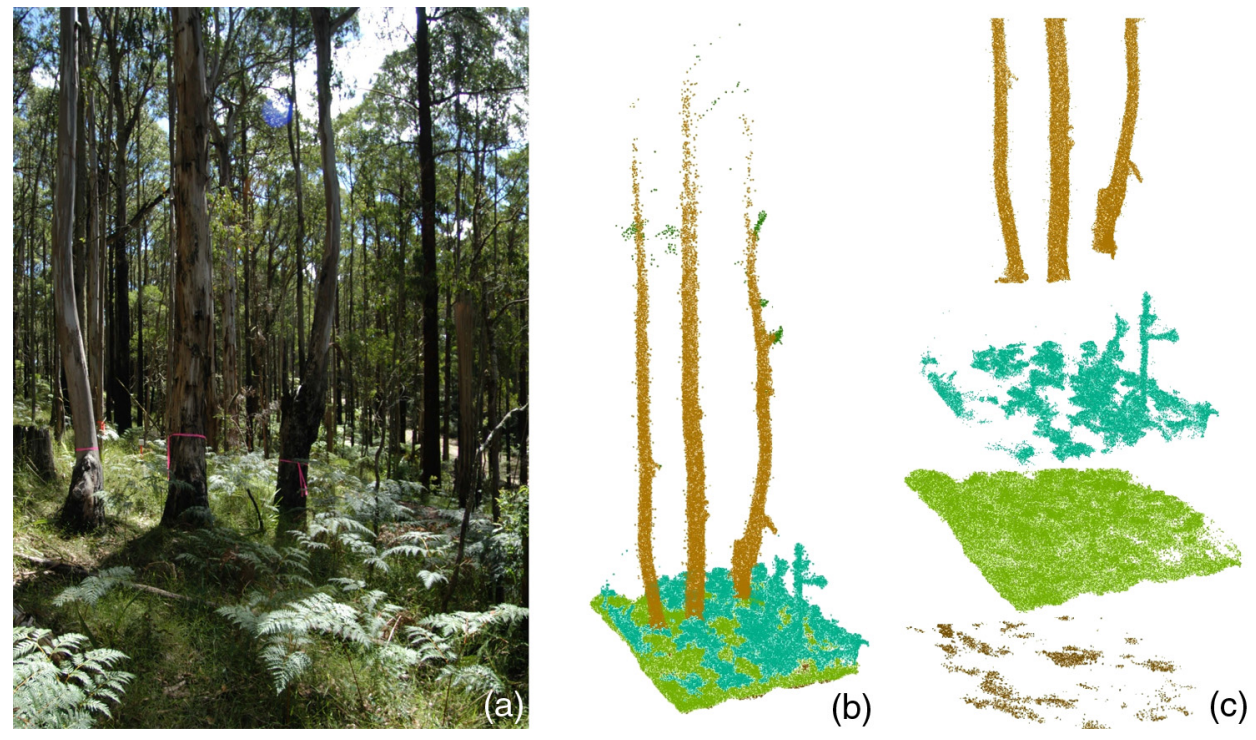

Fig. 5 TLS-derived fuel structural classification compared with a photograph taken at plot 2. (a) A photography of forest fuel. (b) An overview of LiDAR-derived fuel strata. (c) The classified fuel strata from top to bottom, including tree trunks, elevated fuel, near surface fuel, and surface fuel. 
Table 1 Surveyed and TLS-derived fuel characteristics.

\begin{tabular}{|c|c|c|c|c|c|c|c|c|c|}
\hline \multirow[b]{2}{*}{$\begin{array}{l}\text { Plot } \\
\text { ID }\end{array}$} & \multirow[b]{2}{*}{$\begin{array}{c}\text { Sample } \\
\text { ID }\end{array}$} & \multicolumn{4}{|c|}{ Field measured } & \multicolumn{4}{|c|}{ LiDAR-derived bias } \\
\hline & & $\begin{array}{l}\text { Litter- } \\
\text { bed } \\
\text { depth } \\
(\mathrm{cm})\end{array}$ & $\begin{array}{l}\text { Litter } \\
\text { cover } \\
(\%)\end{array}$ & $\begin{array}{l}\text { Near- } \\
\text { surface } \\
\text { plant } \\
\text { cover } \\
(\%)\end{array}$ & $\begin{array}{l}\text { Elevated } \\
\text { fuel plant } \\
\text { cover }(\%)\end{array}$ & $\begin{array}{l}\text { Litter-bed } \\
\text { depth } \\
\text { (cm) }\end{array}$ & $\begin{array}{c}\text { Litter } \\
\text { cover } \\
(\%)\end{array}$ & $\begin{array}{l}\text { Near- } \\
\text { surface } \\
\text { plant } \\
\text { cover } \\
(\%)\end{array}$ & $\begin{array}{l}\text { Elevated } \\
\text { fuel plant } \\
\text { cover (\%) }\end{array}$ \\
\hline 1 & 1 & 2 & 90 & 60 & 50 & 1.2 & 10.0 & 11.3 & 3.5 \\
\hline 1 & 2 & 2 & 90 & 60 & 75 & -0.2 & 10.0 & 4.2 & 0.3 \\
\hline 1 & 3 & 2 & 100 & 100 & 80 & -0.3 & 0.0 & 0.0 & 12.0 \\
\hline 1 & 4 & 6 & 100 & 100 & 30 & -1.0 & 0.0 & 0.0 & 9.7 \\
\hline 1 & 5 & 6 & 100 & 70 & 50 & -1.0 & 0.0 & 4.8 & -5.5 \\
\hline 2 & 1 & 5 & 90 & 40 & 100 & 0.0 & 10.0 & -3.8 & -3.8 \\
\hline 2 & 2 & 6 & 100 & 60 & 80 & -1.0 & 0.0 & 1.1 & -7.1 \\
\hline 2 & 3 & 7 & 100 & 50 & 90 & 1.2 & 0.0 & -2.5 & 1.3 \\
\hline 2 & 4 & 5.5 & 100 & 100 & 50 & -0.5 & 0.0 & 0.0 & 1.0 \\
\hline 2 & 5 & 5 & 90 & 80 & 40 & 0.0 & 10.0 & 4.7 & 0.8 \\
\hline 2 & 6 & 5.5 & 100 & 100 & 50 & -0.5 & 0.0 & -0.7 & -0.9 \\
\hline 3 & 1 & 13 & 100 & 70 & 90 & 1.1 & 0.0 & -2.0 & 2.0 \\
\hline 3 & 2 & 10 & 100 & 30 & 90 & 1.2 & 0.0 & -4.0 & 0.0 \\
\hline 3 & 3 & 7 & 100 & 90 & 100 & -0.4 & 0.0 & 6.0 & 0.0 \\
\hline 3 & 4 & 6 & 80 & 30 & 90 & 0.4 & 1.4 & 1.0 & 5.0 \\
\hline 3 & 5 & 6 & 70 & 30 & 80 & -0.2 & -2.6 & -6.0 & -1.0 \\
\hline 3 & 6 & 5 & 60 & 90 & 90 & -0.1 & 2.9 & 6.0 & 10.0 \\
\hline 3 & 7 & 8 & 100 & 90 & 100 & -0.1 & 0.0 & 0.0 & 0.0 \\
\hline 3 & 8 & 11 & 100 & 90 & 100 & 0.2 & 0.0 & 1.0 & 0.0 \\
\hline 3 & 9 & 9 & 100 & 90 & 50 & -0.1 & 0.0 & 1.0 & -2.0 \\
\hline 3 & 10 & 7 & 100 & 80 & 60 & 0.1 & 0.0 & 3.0 & 0.0 \\
\hline 4 & 1 & 1.5 & 90 & 40 & 15 & 0.1 & 10.0 & 0.0 & -2.0 \\
\hline 4 & 2 & 2 & 90 & 25 & 45 & 0.6 & 7.0 & 5.0 & 8.0 \\
\hline 4 & 3 & 1.5 & 80 & 20 & 60 & -0.1 & 9.0 & 2.0 & -1.0 \\
\hline 4 & 4 & 0.5 & 90 & 30 & 40 & 2.5 & 8.0 & 14.0 & 8.0 \\
\hline 4 & 5 & 3 & 80 & 10 & 20 & -1.6 & 18.0 & -4.0 & 2.0 \\
\hline 4 & 6 & 3.5 & 70 & 30 & 30 & -1.3 & 1.0 & 5.0 & -4.0 \\
\hline 4 & 7 & 2 & 75 & 40 & 40 & 1.7 & 11.0 & 4.0 & 17.0 \\
\hline 4 & 8 & 1 & 50 & 10 & 35 & -0.7 & -6.0 & 2.0 & 6.0 \\
\hline 5 & 1 & 7 & 90 & 60 & 70 & -1.6 & 10.0 & 21.9 & 18.7 \\
\hline 5 & 2 & 2.5 & 85 & 85 & 65 & -1.0 & 13.0 & 10.8 & 11.5 \\
\hline
\end{tabular}


Table 1 (Continued).

\begin{tabular}{|c|c|c|c|c|c|c|c|c|c|}
\hline \multirow[b]{2}{*}{$\begin{array}{l}\text { Plot } \\
\text { ID }\end{array}$} & \multirow[b]{2}{*}{$\begin{array}{c}\text { Sample } \\
\text { ID }\end{array}$} & \multicolumn{4}{|c|}{ Field measured } & \multicolumn{4}{|c|}{ LiDAR-derived bias } \\
\hline & & $\begin{array}{l}\text { Litter- } \\
\text { bed } \\
\text { depth } \\
(\mathrm{cm})\end{array}$ & $\begin{array}{c}\text { Litter } \\
\text { cover } \\
(\%)\end{array}$ & $\begin{array}{l}\text { Near- } \\
\text { surface } \\
\text { plant } \\
\text { cover } \\
(\%)\end{array}$ & $\begin{array}{l}\text { Elevated } \\
\text { fuel plant } \\
\text { cover }(\%)\end{array}$ & $\begin{array}{l}\text { Litter-bed } \\
\text { depth } \\
(\mathrm{cm})\end{array}$ & $\begin{array}{l}\text { Litter } \\
\text { cover } \\
(\%)\end{array}$ & $\begin{array}{l}\text { Near- } \\
\text { surface } \\
\text { plant } \\
\text { cover } \\
(\%)\end{array}$ & $\begin{array}{l}\text { Elevated } \\
\text { fuel plant } \\
\text { cover (\%) }\end{array}$ \\
\hline 5 & 3 & 3 & 100 & 85 & 55 & -1.1 & 0.0 & 12.5 & -14.8 \\
\hline 5 & 4 & 5 & 95 & 75 & 65 & -2.0 & 5.0 & 19.9 & 20.3 \\
\hline 5 & 5 & 2.5 & 90 & 75 & 60 & -0.8 & 10.0 & 14.8 & 0.5 \\
\hline 5 & 6 & 3.5 & 100 & 60 & 55 & -1.5 & 0.0 & 18.5 & 1.0 \\
\hline 5 & 7 & 7 & 100 & 80 & 45 & -3.3 & 0.0 & 16.0 & -6.1 \\
\hline 5 & 8 & 5 & 95 & 80 & 70 & -2.5 & 5.0 & 16.2 & 19.6 \\
\hline 6 & 1 & 5 & 100 & 90 & 0 & 0.0 & 0.0 & 5.5 & 0.3 \\
\hline 6 & 2 & 7 & 90 & 80 & 40 & -0.5 & 10.0 & 3.4 & -22.2 \\
\hline 6 & 3 & 10 & 100 & 80 & 70 & -1.3 & 0.0 & 1.5 & 15.4 \\
\hline 6 & 4 & 2 & 80 & 85 & 80 & 0.2 & 15.1 & -1.7 & 11.2 \\
\hline 6 & 5 & 5 & 100 & 85 & 40 & -0.2 & 0.0 & -1.7 & -8.9 \\
\hline 6 & 6 & 5 & 100 & 90 & 30 & 0.7 & 0.0 & 5.5 & -9.3 \\
\hline 6 & 7 & 4 & 100 & 70 & 40 & -0.6 & 0.0 & 0.6 & 30.3 \\
\hline 6 & 8 & 3 & 90 & 80 & 60 & -1.5 & 8.1 & 9.6 & -9.6 \\
\hline
\end{tabular}

forest fuel strata stratification [Fig. 5(b)] compared to the photograph in Fig. 5(a). The tree trunks in Fig. 5(c) are separated from branches and leaves compared with the initial fuel layer classification in Fig. 3(b). The overstory fuels misclassified by directly applying the height difference are also correctly reassigned as elevated shrubs.

Data on surface fuel depth at 45 sampling locations were collected to validate the TLSderived fuel structural characteristics (Table 1). The residuals were normally distributed and the input variables followed the assumptions of linear regression. The $R^{2}$ value of 0.9 and RMSE values of $1.1 \mathrm{~cm}$ were produced by comparing the TLS-derived surface fuel depths

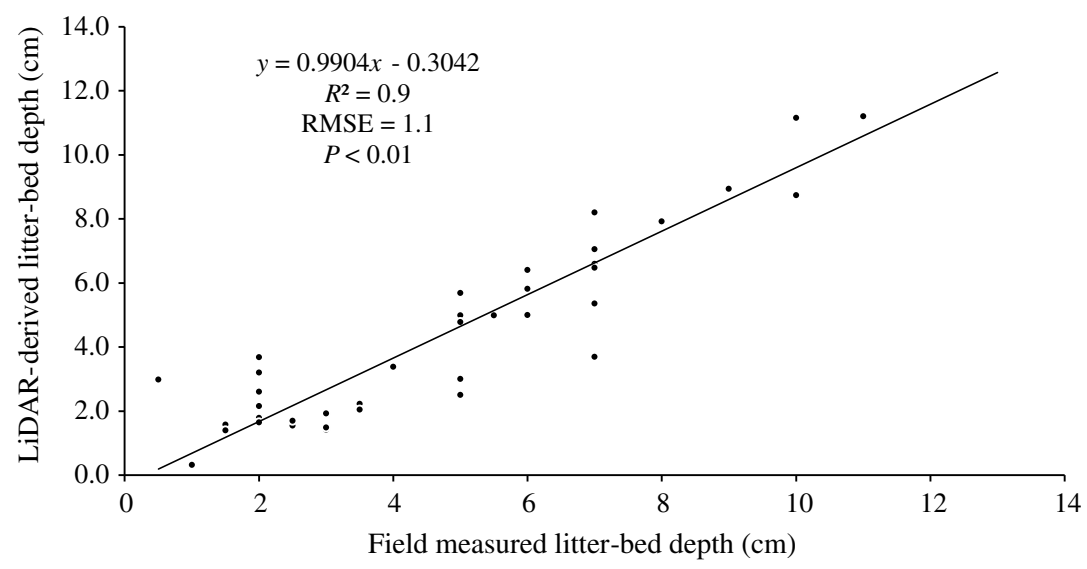

Fig. 6 Scattergram of TLS-derived against measured litter bed depth with linear regression $(n=45)$. (Note: some sample points are very close to each other and appear overlapped.) 
Table 2 The correlation coefficients among fuel layers.

\begin{tabular}{lcccc}
\hline \hline Correlation coefficient & $\begin{array}{c}\text { Litter-bed } \\
\text { depth (cm) }\end{array}$ & $\begin{array}{c}\text { Litter } \\
\text { cover }(\%)\end{array}$ & $\begin{array}{c}\text { Near-surface } \\
\text { plant cover (\%) }\end{array}$ & $\begin{array}{c}\text { Elevated } \\
\text { plant cover (\%) }\end{array}$ \\
\hline Litter-bed depth (cm) & 1 & 0.2092 & 0.1145 & 0.4482 \\
Litter cover (\%) & - & 1 & 0.4583 & 0.0129 \\
Near-surface plant cover (\%) & - & - & 1 & 0.062 \\
Elevated plant cover (\%) & - & - & - & 1 \\
\hline \hline
\end{tabular}

with the surveyed depths (Fig. 6). A correlation coefficient value of 0.4482 described in Table 2 shows a strong relationship between the surface litter fuel depth and elevated fuel percentage cover.

Direct application of the initial fuel layer classification based on vertical height ranges resulted in tree trunks not being detected and misclassification occurring (Fig. 3); therefore, a reclassification of fuel strata was necessary before assessing fuels. The GIS and TLSbased method had very small discrepancies compared with the observed values at each fuel strata. The relationship was found to be statistically significant, therefore, we can have confidence in using TLS to classify understory fuel layers, and also to represent forest fuel coverage for surface, near-surface fuel, and elevated fuel layers (Fig. 7). The TLS-derived fuel percentage covers had a statistically significant relationship with surveyed results at surface fuel layer $\left(R^{2}=0.8, \mathrm{RMSE}=5.4 \%\right)$, near-surface fuel layer $\left(R^{2}=0.9, \mathrm{RMSE}=6.9 \%\right)$, and elevated fuel layer $\left(R^{2}=0.9\right.$, RMSE $\left.=9.9 \%\right)$ [Figs. 7(a)-7(c)]. The total of TLS-derived fuel cover against field measured values produced values of $R^{2}(0.9)$ and RMSE (7.6\%) [Fig. 7(d)]. A normal distribution of the data was confirmed by a visual interpretation of histogram and normal probability plot of residuals.


Fig. 7 TLS-derived and field measured fuel cover scattergram with linear regression. (a) Litter cover $(n=45)$, (b) near-face cover $(n=45)$, (c) elevated cover $(n=45)$, (d) understory fuel cover $(n=135)$. (Note: some sample points are very close to each other and appear overlapped.) 


\section{Discussion}

Current fire danger rating systems and fire behavior prediction models share a common challenge in quantifying fuels, since the fuel varies between sites and even within homogeneous vegetation depending on forest types, local environment, and previous fire disturbances. ${ }^{53-55}$ Accurately describing forest surface fuel load and fuel structure is significant for understanding bushfire behavior and suppression difficulties. Traditionally, surface fuel load is determined by field sampling, oven drying, and weighing, ${ }^{3,56,57}$ which can be time and labor intensive at large scales. McArthur's positive relationships ${ }^{3}$ between surface fuel load and surface fuel depth have been used as a rapid method to support fire hazard-reduction burns in Eucalypt forests in Australia, instead of directly measuring surface fuel load. In addition, forest vertical structure is a function of species composition, microclimate, site quality, and topography, which has a significant influence on productivity and fuel accumulation. ${ }^{15,58}$ Therefore, the development of accurate, reliable, and efficient methods to quantify forest surface fuel depth and fuel strata can be useful for surface fuel load estimation and fire hazard assessment.

In our study, the fuel structure classification based on the integration between TLS and GIS was proposed as a means to provide accurate, consistent, and objective information for describing forest fuel characteristics. It could be used to assist visual fuel hazard assessment when visual assessment is restricted by local complex terrain. It could also be useful for validating the result of visual assessment, which is error-prone and subjective. The TLS-derived surface fuel depth is also of interest in surface fuel load estimation for assessing fuel hazards as well as predicting fire behavior potential.

Currently accepted methods used by fire fighters and land managers for field measurements are susceptible to bias. To be more specific, during the fuel assessment, the observer measures the surface fuel depth by direct measurements at one site, and the finalized depth is determined by an average value of five measurements within the site. The observer also assesses the percentage cover of the vegetation for each fuel layer based on his or her empirical knowledge and visual assessing skills. Field-based surface fuel and near-surface fuel assessment can be more straightforward compared with assessing elevated shrubs because of the heights of the fuel layer and the position of the observer. Visually assessing elevated fuels may also create inconsistency as a result of individual survey error and local environment factors. Therefore, currently used visual assessment could be less objective compared with TLS data.

In contrast, this GIS-based fuel structure classification can be used to effectively and efficiently assess forest fuel hazard and to estimate forest fuel inventory. The complex GIS procedure is edited, compiled, and implemented in ArcGIS ModelBuilder. It can be used to automatically classify fuel strata and quantify surface fuel depth for assessing forest fuel hazards for open eucalypt forests with complex understory vegetation and trains. The quantification of forest fuel structure and depth can assist surface fuel load estimation for fire-related management and operations.

TLS is sensitive to vertical and horizontal changes in vegetation availability. ${ }^{38}$ The plots 5 and 6 trend to have more bias in elevated fuel cover (Table 1). These slight discrepancies indicate visual assessment can be more subjective in describing structural information of elevated fuel. Table 2 describes the independence among layers based on their correlation coefficients. The percentage cover of elevated fuel is not correlated with any other fuel layers, but it has a strong positive relationship with surface litter depth. From a fuel accumulation concept, litter fuel accumulates over time depending on the difference between rates of fuel accession and decomposition. ${ }^{5}$ Understory shrubs contribute to increasing fuel accession rates, thus litter accumulates with the similar environmental conditions and forest type. ${ }^{1}$ A positive relationship between fuel cover at surface layer and near-surface layer (Table 2) reflects understory recovery with litter fuel accumulation and lower vegetation regrowth after the previous fire event. ${ }^{4}$

However, it should be noted that the classification could be affected by the choice of slicing interval and threshold. For instance, increasing the thickness of horizontal slices raises both accuracy and processing time. We suggest using $1 \mathrm{~m}$ as the height interval; the thinner the slice, the more processing time required. The accuracy of reference trunk identification could be affected by choosing the threshold $(r)$ value. A rise in $r$ value may lead to 
overestimation of the diameter of the stems. The sensitivities of the thickness of slices and the $r$ value need to be tested. This method is also restricted by empirical knowledge of forest fire history and the minimum height of the tree branches $(h)$.

Tree heights, DBHs, and number of trees are not validated since they are not essential for assessing fuel hazard. For future study, DBHs could be tested in order to assess the accuracy of TLS-derived forest inventory. An overall forest fuel hazard assessment requires fuel depth and percentage cover at individual fuel layers, as well as a description of bark fuel as inputs. Bark fuel can be described by ease of ignition, the way it attaches to the trunks, the quantity of combustible bark, and burn out time according to the thickness, size, and shape of bark pieces. However, LiDAR has difficulty in assessing bark fuels, since assessing bark fuels requires more complex empirical knowledge to describe the texture and to assess the effect of bark on suppression difficulties. The application of TLS in quantifying and assessing forest fuels is restricted by scanning angle, scale (vertical and horizontal), and position. In order to overcome these restrictions, terrestrial and airborne LiDAR observations can be integrated to provide a more complete forest fuel hazard assessment.

\section{Conclusion}

Traditional wildland fuel load measurements are based on destructive samplings in order to directly measure the dry weight of fuels, which is time and labor intensive. The current sampling-based visual assessment is rapid, but it can be subjective when extrapolated to infer fuels across larger landscape scales. LiDAR technology can provide more efficient, consistent, and accurate information for measuring forest vegetation biomass. This paper has introduced an approach based on an integration between TLS and GIS to automatically classify forest fuel strata and assess fuel characteristics. The complex GIS-based processing procedures were edited and compiled in ArcGIS ModelBuilder, and then implemented with an ArcGIS toolkit. The outcome suggests that the integrated method can provide objective, consistent, and efficient information to describe fuel structural characteristics for forest fuel hazard assessment and forest fuels management as an alternative of the visual assessment. Additionally, accurate and efficient quantification of fuel structure and surface fuel depth has its significance in estimation of forest surface fuel load. The proposed method is beneficial for understanding fire behavior in multilayered Eucalypt forests.

\section{Acknowledgments}

Appreciation is extended to Monash University and the Bushfire and Natural Hazards CRC for assisting this research through providing PhD scholarships. Special thanks to Robert Zlot, CSIRO Australia for providing the Zebedee 3-D Mapping System, and to Nick Bauer, DELWP VIC Australia for providing useful feedback on a draft of this paper. Sincere gratitude to Musa Kilinc for his guidance and support in early phase of the project, and to Adam Leavesley, Thomas Jovanovic, Senthuran Arunthavanathan, Dean Yulindra Affandi, Yang Di, Zhan Wang, Saadia Majeed, Yingying Qiao, and Darren Hocking for their field work support.

\section{References}

1. J. S. Gould et al., Project Vesta: Fire in Dry Eucalypt Forest: Fuel Structure, Fuel Dynamics and Fire Behaviour, p. 218, CSIRO Publishing, Melbourne (2008).

2. W. L. McCaw, "Measurement of fuel quantity and structure for bushfire research and management," in Bushfire Modelling and Fire Danger Rating Systems, pp. 147-155, CSIRO, Division of Forestry, Canberra (1991).

3. A. G. McArthur, Control Burning in Eucalypt Forests, Forestry and Timber Bureau, Leaflet, Canberra, Australia (1962).

4. B. Fox, M. Fox, and G. McKay, "Litter accumulation after fire in a eucalypt forest," Aust. J. Bot. 27(2), 157-165 (1979).

5. G. Peet, "Litter accumulation in jarrah and karri forests," Aust. For. 35(4), 258-262 (1971). 
6. D. Simmons and R. Adams, "Fuel dynamics in an urban fringe dry sclerophyll forest in Victoria," Aust. For. 49, 149-154. (1986).

7. R. Raison, P. Woods, and P. Khanna, "Dynamics of fine fuels in recurrently burnt eucalypt forests," Aust. For. 46(4), 294-302 (1983).

8. R. H. Luke and A. G. McArthur, Bush Fires in Australia, p. 368, Australian Government Publishing Service, Canberra (1978).

9. P. J. Watson, S. H. Penman, and R. A. Bradstock, "A comparison of bushfire fuel hazard assessors and assessment methods in dry sclerophyll forest near Sydney, Australia," Int. J. Wildland Fire 21(6), 755-763 (2012).

10. R. E. Keane, R. Burgan, and J. van Wagtendonk, "Mapping wildland fuels for fire management across multiple scales: integrating remote sensing, GIS, and biophysical modeling," Int. J. Wildland Fire 10(4), 301-319 (2001).

11. D. V. Sandberg, R. D. Ottmar, and G. H. Cushon, "Characterizing fuels in the 21 st century," Int. J. Wildland Fire 10(3/4), 381-387 (2001).

12. F. Chen et al., "Assessing the susceptibility of semiarid rangelands to wildfires using terra MODIS and Landsat thematic mapper data," Int. J. Wildland Fire 20(5), 690-701 (2011).

13. J. S. Gould and M. Cruz, "Australian fuel classification-update," in CSIRO Bushfire Behaviour Science Symp., Canberra (2013).

14. H. G. Maas et al., "Automatic forest inventory parameter determination from terrestrial laser scanner data," Int. J. Remote Sens. 29(5), 1579-1593 (2008).

15. R. O. Dubayah and J. B. Drake, "Lidar remote sensing for forestry," J. For. 98(6), 44-46 (2000).

16. K. Lim et al., "LiDAR remote sensing of forest structure," Prog. Phys. Geog. 27(1), 88-106 (2003).

17. H. E. Andersen, R. J. McGaughey, and S. E. Reutebuch, "Estimating forest canopy fuel parameters using LIDAR data," Remote Sens. Environ. 94(4), 441-449 (2005).

18. J. S. Gould, W. L. McCaw, and N. P. Cheney, "Quantifying fine fuel dynamics and structure in dry eucalypt forest (Eucalyptus marginata) in Western Australia for fire management," For. Ecol. Manage. 262(3), 531-546 (2011).

19. M. A. Lefsky et al., "Lidar Remote Sensing for Ecosystem Studies Lidar, an emerging remote sensing technology that directly measures the three-dimensional distribution of plant canopies, can accurately estimate vegetation structural attributes and should be of particular interest to forest, landscape, and global ecologists," BioScience 52(1), 19-30 (2002).

20. S. C. Popescu, R. H. Wynne, and R. F. Nelson, "Measuring individual tree crown diameter with lidar and assessing its influence on estimating forest volume and biomass," Can. J. Remote Sens. 29(5), 564-577 (2003).

21. E. Naesset, "Estimating timber volume of forest stands using airborne laser scanner data," Remote Sens. Environ. 61(2), 246-253 (1997).

22. D. L. Gaveau and R. A. Hill, "Quantifying canopy height underestimation by laser pulse penetration in small-footprint airborne laser scanning data," Can. J. Remote Sens. 29(5), 650-657 (2003).

23. J. Pitkänen et al., "Adaptive methods for individual tree detection on airborne laser based canopy height model," Int. Arch. Photogramm., Remote Sens. Spat. Inf. Sci. 36(8), 187-191 (2004).

24. B. Koch, U. Heyder, and H. Weinacker, "Detection of individual tree crowns in airborne lidar data," Photogramm. Eng. Remote Sens. 72(4), 357-363 (2006).

25. S. C. Popescu, "Estimating biomass of individual pine trees using airborne lidar," Biomass Bioenergy 31(9), 646-655 (2007).

26. J. C. Suárez et al., "Use of airborne LiDAR and aerial photography in the estimation of individual tree heights in forestry," Comput. Geosci. 31(2), 253-262 (2005).

27. T. Hermosilla et al., "Estimation of forest structure and canopy fuel parameters from small-footprint full-waveform LiDAR data," Int. J. Wildland Fire 23(2), 224-233 (2014).

28. M. K. Jakubowksi et al., "Predicting surface fuel models and fuel metrics using Lidar and CIR imagery in a dense, mountainous forest," Photogramm. Eng. Remote Sens. 79(1), 3749 (2013). 
29. X. Liu, "Airborne LiDAR for DEM generation: some critical issues," Prog. Phys. Geog. 32(1), 31-49 (2008).

30. D. A. Zimble et al., "Characterizing vertical forest structure using small-footprint airborne LiDAR," Remote Sens. Environ. 87(2), 171-182 (2003).

31. B. Devereux et al., "The potential of airborne lidar for detection of archaeological features under woodland canopies," Antiquity 79(305), 648-660 (2005).

32. M. Dassot, T. Constant, and M. Fournier, "The use of terrestrial LiDAR technology in forest science: application fields, benefits and challenges," Ann. For. Sci. 68(5), 959-974 (2011).

33. M. Thies and H. Spiecker, "Evaluation and future prospects of terrestrial laser scanning for standardized forest inventories," Forest 2(2.2), 1 (2004).

34. J. A. Bellian, C. Kerans, and D. C. Jennette, "Digital outcrop models: applications of terrestrial scanning lidar technology in stratigraphic modeling," J. Sediment. Res. 75(2), 166-176 (2005).

35. C. Hopkinson et al., "Assessing forest metrics with a ground-based scanning lidar," Can. J. For. Res. 34(3), 573-583 (2004).

36. J. Ryding et al., "Assessing handheld mobile laser scanners for forest surveys," Remote Sens. 7(1), 1095-1111 (2015).

37. G. J. Newnham et al., "Terrestrial laser scanning for plot-scale forest measurement," Curr. For. Rep. 1(4), 239-251 (2015).

38. E. L. Loudermilk et al., "Ground-based LIDAR: a novel approach to quantify fine-scale fuelbed characteristics," Int. J. Wildland Fire 18(6), 676-685 (2009).

39. M. Simonse et al., "Automatic determination of forest inventory parameters using terrestrial laserscanning," in ScandLaser Scientific Workshop on Airborne Laser Scanning of Forests, Vol. 2003, pp. 252-258 (2003).

40. N. Pfeifer and D. Winterhalder, "Modelling of tree cross sections from terrestrial laser scanning data with free-form curves," in Int. Archives of Photogrammetry, Remote Sensing and Spatial Information Sciences, Vol. 36, No. Part 8, pp. W2 (2004).

41. J. F. Côté et al., "The structural and radiative consistency of three-dimensional tree reconstructions from terrestrial lidar," Remote Sens. Environ. 113(5), 1067-1081 (2009).

42. L. M. Moskal and G. Zheng, "Retrieving forest inventory variables with terrestrial laser scanning (TLS) in urban heterogeneous forest," Remote Sens. 4(1), 1-20 (2011).

43. T. Aschoff and H. Spiecker, "Algorithms for the automatic detection of trees in laser scanner data," in Int. Archives of Photogrammetry, Remote Sensing and Spatial Information Sciences, Vol. 36, No. Part 8, p. W2 (2004).

44. J. G. Henning and P. J. Radtke, "Detailed stem measurements of standing trees from ground-based scanning lidar," For. Sci. 52(1), 67-80 (2006).

45. P. J. Besl and N. D. McKay, "Method for registration of 3-D shapes," Proc. SPIE 1611, 586606 (1992).

46. M. Bosse, R. Zlot, and P. Flick, "Zebedee: design of a spring-mounted 3-D range sensor with application to mobile mapping," IEEE Trans. Rob. 28(5), 1104-1119 (2012).

47. B. Gorte and N. Pfeifer, "Structuring laser-scanned trees using 3D mathematical morphology," in Int. Archives of Photogrammetry and Remote Sensing, Vol. 35, No. B5, pp. 929933 (2004).

48. J. L. Widlowski et al., "Rayspread: a virtual laboratory for rapid BRF simulations over 3-D plant canopies," in Computational Methods in Transport, Vol. 48, pp. 211-231, Springer Verlag, Berlin, Heidelberg (2006).

49. F. Hosoi and K. Omasa, "Voxel-based 3-D modeling of individual trees for estimating leaf area density using high-resolution portable scanning lidar," IEEE Trans. Geosci. Remote Sens. 44(12), 3610-3618 (2006).

50. H. Xu, N. Gossett, and B. Chen, "Knowledge and heuristic-based modeling of laser-scanned trees," ACM Trans. Graph. 26(4), 19 (2007).

51. E. M. Rowell, C. A. Seielstad, and R. D. Ottmar, "Development and validation of fuel height models for terrestrial lidar-RxCADRE 2012," Int. J. Wildland Fire 25(1), 38-47 (2016).

52. S. M. Marselis et al., "Deriving comprehensive forest structure information from mobile laser scanning observations using automated point cloud classification," Environ. Modell. Software 82, 142-151 (2016). 
53. J. E. Deeming and J. K. Brown, "Fuel models in the national fire-danger rating system," J. For., 73(6), 347-350 (1975).

54. J. S. Gould et al., "National fire behaviour knowledge base-bringing together the best information for best decisions," (2014).

55. K. G. Tolhurst, B. Shields, and D. Chong, "Phoenix: development and application of a bushfire risk management tool," Aust. J. Emerg. Manage. 23(4), 47 (2008).

56. G. J. McCarthy, "Assessment of overall fuel hazard for a site and its implications for both strategic fuel management and first attack success probability," in 13th Conf. on Fire and Forest Meteorology, p. 79, International Association of Wildland Fire, Lorne, Australia (1996).

57. G. J. McCarthy, K. G. Tolhurst, and K. Chatto, Overall Fuel Hazard Guide, Department of Natural Resources \& Environment, East Melbourne, Victoria (1998).

58. R. O. Dubayah and J. B. Drake, "Lidar remote sensing for forestry," J. For. 98(6), 44-46 (2000).

Yang Chen, BSc, MSc, is a PhD student working in LiDAR and forest fires funded by Monash University and BNHCRC. She was awarded the Royal Society of Victoria's Young Scientists Research Prize 2016. She published papers regarding LiDAR application in forestry and also presented her study in various academic conferences, including SPIE Remote Sensing 2016, Fire Behavior and Fuel 2016, AFAC 2015 and 2016. As a member of SPIE, she has also served JARS as a reviewer since 2013 .

Xuan Zhu is a senior lecturer in GIS and remote sensing at Monash University. His main fields of research are GIS, remote sensing, knowledge-based systems, decision support systems, and their applications to resource and environmental management.

Marta Yebra received her PhD degree from the University of Alcala, Spain, in 2008. She is currently a research fellow at the Australian National University and cochair of the observational data working group of the Australian Energy and Water Exchange Research Initiative. Her main background is in remote sensing of vegetation biophysical properties, such as fuel load and moisture content for spatial fire risk analysis, and canopy conductance for carbon sequestration and water balance studies.

Sarah Harris is a research fellow in the School of Earth, Atmosphere and Environment at Monash University. Her research focuses on the variability and change in fire weather, climate-wildfire links and prediction of seasonal wildfire activity. She is also experienced in using remotely sensed data to map the extent and severity of fires.

Nigel Tapper holds a personal chair in environmental science at Monash University. He is a climate science specialist working across observations, modelling and remote sensing. He has particular interests in climate adaptation and climate impacts, including climate-dust, climatehuman health, and climate-fire interactions. 